\title{
Rancang Bangun Sistem Informasi Pelaporan Penyampaian SPT Masa Oleh Wajib Pajak
}

\author{
Risa Septia Dewi ${ }^{1,{ }^{*}}$, Kusdarnowo Hantoro ${ }^{1}$, Sri Rejeki ${ }^{1}$ \\ 1 Teknik Informatika; Universitas Bhayangkara Jakarta Raya; JI Raya Perjuangan No. 81 \\ Bekasi Utara, (021) 88955882; risaseptiadewi120911@gmail.com; \\ kusdarnowo@dsn.ubharajaya.ac.id; sri rejeki@dsn.ubharajaya.ac.id \\ * Korespondensi: e-mail: kusdarnowo@dsn.ubharajaya.ac.id
}

Diterima:10 Mei 2020; Review:11Mei 2020; Disetujui: 27 Mei 2020; Diterbitkan: 17 Juni 2020

\begin{abstract}
Tax Period Notification Letter (SPT) is submitted by the Taxpayer to the Directorate General of Taxes through the Tax Service Office (KPP) manually so that there is often a buildup of queue reporting services for submitting Periodic Tax. To reduce delays in submitting a mobile-based system or application was built to improve services in delivering the Annual Tax Return report. Periodic SPT features are available complete including Income Tax Article 21/26, Article 22, Article 23/26, Article 25, Article 4 paragraph 2 and Article 15 which are designed using the Extreem Programming method. The research method uses descriptive methods that are carried out to get a picture or description of a situation objectively, systematically, factually and accurately.
\end{abstract}

Keywords: Taxes, tax returns, queues, taxpayers, Tax Service Office

\begin{abstract}
Abstrak
Surat Pemberitahuan (SPT) Masa pajak disampaikan oleh Wajib Pajak kepada Ditjen Pajak melalui Kantor Pelayanan Pajak (KPP) secara manual sehingga sering terjadi penumpukan antrian layanan pelaporan penyampaian SPT Masa. Untuk mengurangi keterlambatan penyampaian maka dibangun sistem atau aplikasi mobile berbasis Android untuk meningkatkan pelayanan dalam menyampaikan laporan SPT Masa. Fitur-fitur SPT Masa cukup lengkap tersedia meliputi PPh (Pajak Penghasilan) Pasal 21/26, Pasal 22, Pasal 23/26, Pasal 25, Pasal 4 ayat 2 dan Pasal 15 yang dirancang menggunakan metode Extreem Programming. Metode penelitian menggunakan metode deskriptif yang dilakukan untuk mendapatkan gambaran atau deskripsi tentang suatu keadaan secara obyektif, sistematis, faktual dan akurat.
\end{abstract}

Kata kunci: Pajak, SPT Masa, Antrian, Wajib Pajak, KPP

\section{Pendahuluan}

Pemanfaatan TIK secara efektif di kalangan aparatur pemerintahan, diharapkan selain kualitas layanan masyarakat makin meningkat, juga terwujud tata kelola pemerintahan yang baik dan bersih (Respati, 2020). Di era globalisasi seperti saat ini, tidak heran apabila kemajuan teknologi informasi dan komunikasi dapat menjanjikan efisiensi, kecepatan penyampaian informasi, keterjangkauan, dan transparansi, tidak terkecuali pada pemerintahan. Terlebih, dalam era otonomi daerah saat ini perlu untuk mewujudkan pemerintahan yang baik (good governance) dengan menggunakan teknologi informasi dan komunikasi atau biasa disebut $e$ - 
government (Prakoso et al., 2019)(Wahyu Hidayat Ibrahim, 2017) Pada Pasal 4 UndangUndang Nomor 25 Tahun 2009 tentang Pelayanan Publik dijelaskan tentang asas-asas penyelenggaraan pelayanan publik yang sangat berkaitan dengan penerapan e-government, terutama dalam perwujudan asas huruf $\mathrm{f}$, yaitu partisipatif, huruf $\mathrm{h}$ tentang keterbukaan, huruf $\mathrm{I}$ tentang akuntabilitas, huruf $\mathrm{k}$, yaitu ketepatan waktu, dan huruf I tentang kecepatan, kemudahan, dan keterjangkauan. Juga pada Pasal 23 ayat (1) Undang-Undang Nomor 25 Tahun 2009 tentang Pelayanan Publik, disebutkan bahwa dalam rangka memberikan dukungan informasi terhadap penyelenggaraan pelayanan publik perlu diselenggarakan Sistem Informasi yang bersifat nasional dan ayat (4) dijelaskan bahwa Penyelenggara berkewajiban mengelola Sistem Informasi yang terdiri atas sistem informasi elektronik atau nonelektronik, sekurangkurangnya meliputi; profil penyelenggara, profil pelaksana, standar pelayanan, maklumat pelayanan, pengelola pengaduan dan penilaian kinerja(Kesadaran, Pemahaman, Pelayanan, \& Sanksi, 2017).Definisi dari World Bank (2015) tentang e-government.

"Penggunaan teknologi informasi (seperti Wide Area Network, Internet, dan komunikasi seluler) oleh lembaga pemerintah memiliki kemampuan untuk merubah hubungan dengan warga negara, bisnis, dan perangkat pemerintahan lainnya. Teknologi ini dapat melayani berbagai tujuan yang berbeda: layanan pemerintah yang lebih baik kepada warga negara, meningkatkan interaksi dengan bisnis dan industri, pemberdayaan warga negara melalui akses ke informasi, atau manajemen pemerintah yang lebih efisien. Manfaat yang dihasilkan yaitu penurunan korupsi, peningkatan transparansi, kenyamanan yang semakin baik, pertambahan pendapatan, dan / atau pengurangan biaya-biaya".

Dalam rangka peningkatan pertambahan pendapatan Negara bagi pembangunan, yaitu bersumber dari pajak. Dana dari penerimaan pajak sebagai sumber utama APBN dialokasikan untuk mendanai berbagai pengeluaran negara untuk kemakmuran rakyat. Begitu besarnya peranan pajak dalam APBN, maka usaha untuk meningkatkan penerimaan pajak terus dilakukan oleh pemerintah yang dalam hal ini merupakan tugas dari Direktorat Jenderal Pajak. Berbagai upaya dilakukan Direktorat Jenderal Pajak agar penerimaan pajak maksimal, antara lain adalah dengan ekstensifikasi dan intensifikasi pajak.(Kesadaran et al., 2017)Ekstensifikasi ditempuh dengan meningkatkan jumlah wajib pajak yang aktif, sedangkan intensifikasi dapat ditempuh melalui meningkatkan kualitas aparatur perpajakan, pelayanan prima terhadap wajib pajak, dan pembinaan kepada para wajib pajak, pengawasan administratif, pemeriksaan, penyidikan dan penagihan pasif dan aktif, penegakan hukum serta meningkatkan kepatuhan wajib pajak. Kepatuhan memenuhi kewajiban perpajakan secara sukarela merupakan tulang punggung self assessment system. Wajib pajak bertangggung jawab menetapkan sendiri kewajiban perpajakan dan kemudian secara akurat dan tepat. waktu membayar dan melaporkan pajak tersebut. Penerapan self assessment system diharapkan mampu meningkatkan kesadaran wajib pajak.(Prakoso et al., 2019)

Surat Pemberitahuan (SPT) Masa pajak saat ini disampaiakan oleh Wajib Pajak kepada Ditjen Pajak melalui Kantor Pelayanan Pajak (KPP) secara manual. SPT Masa tersebut 
disampaikan dalam bentuk kertas yang sudah disediakan oleh Kantor Pelayanan Pajak (KPP). Banyaknya tumpukan kertas yang ada di KPP seringkali menimbulkan antrian yang melebihi batas, sehingga Wajib Pajak tidak bisa melaporkan SPT Masa karena terbatas oleh jam kerja pelayanan KPP. Permasalahan lain yaitu masih banyaknya Wajib Pajak yang terlambat melaporkan SPT Masa nya atau bahkan tidak melaporkan SPT Masa nya dikarenakan oleh kesibukan ataupun aktivitas mereka sehari-hari.

Direktorat Jenderal Pajak (DJP) saat ini sudah membuatkan aplikasi Sistem Informasi Direktorat Jenderal Pajak (SIDJP) berbasis web browser dan juga berbasis mobile dalam hal pelaporan penyampaian SPT Tahunan wajib pajak orang pribadi maupun badan usaha melalui aplikasi E- Filling (E-Fin) dan E-SPT tapi belum menjangkau Wajib Pajak untuk SPT Masa Pajak. Inovasi pelayanan pajak untuk Wajib Pajak dalam menyampaikan laporan SPT Masa berbasis mobile ini diharapkan dapat mengurangi penumpukan antrian Wajib Pajak dan untuk mengurangi keterlambatan laporan penyampaian yang dilakukan oleh Wajib Pajak baik itu SPT Masa Nihil maupun SPT Masa Kurang Bayar atau Lebih Bayar.

\section{Metode Penelitian}

Desain penelitian yang digunakan didalam penelitian ini yaitu dengan Metode Deskriptif, yang dilakukan dengan tujuan untuk memberikan gambaran atau deskripsi tentang suatu keadaan secara objektif, sistematis, factual dan akurat.(Editors \& Sharda, 2017)

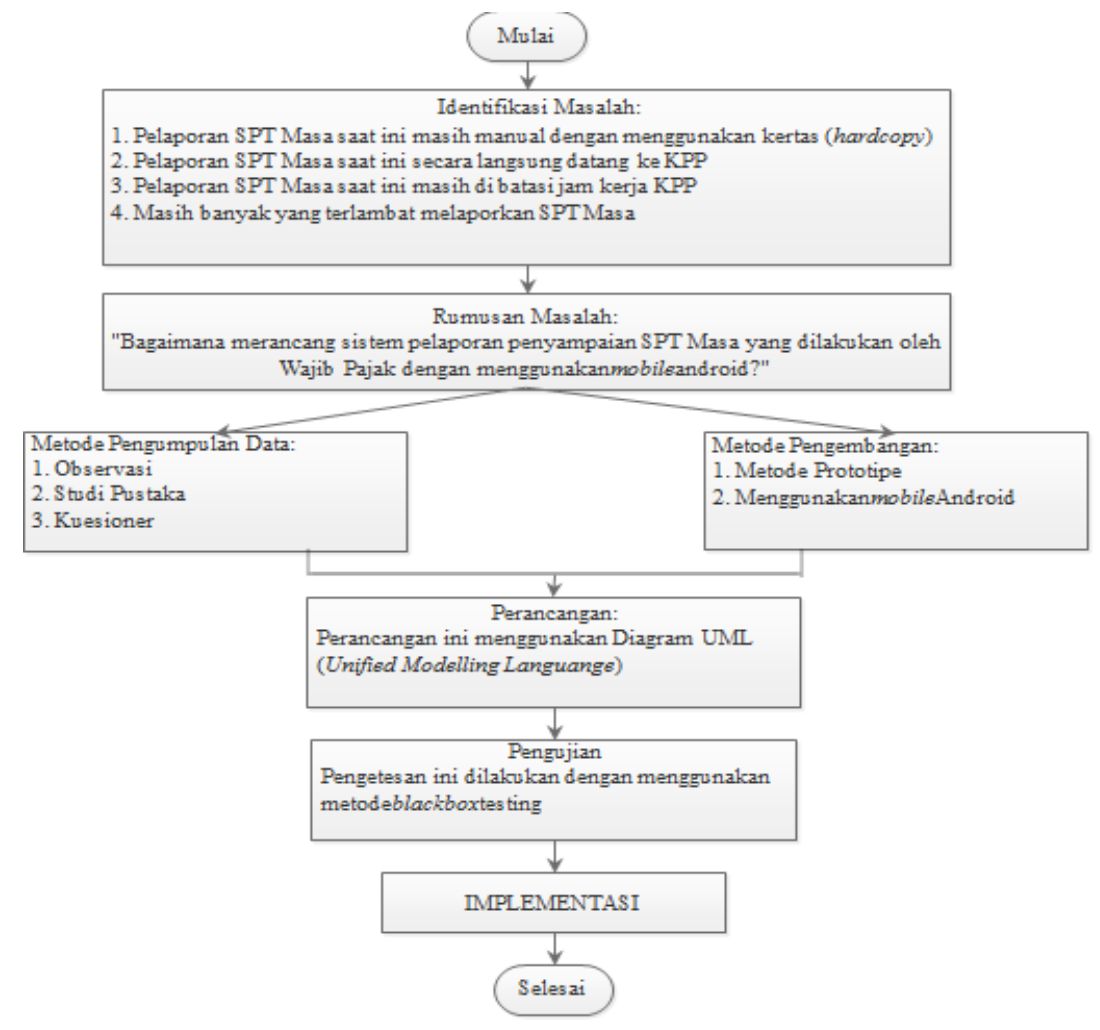

Sumber: Hasil Penelitian (2019)

Gambar 1. Kerangka Penelitian 
Metode Pengumpulan Data, terdiri dari: a) Studi Literatur, Studi literatur adalah pengumpulan data melalui buku-buku, jurnal, halaman web, makalah serta bacaan lain yang sesuai dengan topik yang dibahas. b) Studi Lapangan, Studi lapangan adalah pengumpulan data dengan 2 cara yaitu: 1) Observasi, Tahap observasi adalah pengumpulan data dengan mengadakan penelitian dan peninjauan langsung ke KPP Jakarta Koja. WawancaraPada metode pengumpulan data ini penulis mewancarai seseorang yang ahli dalam bidangnya atau melakukan diskusi dengan seseorang yang mengerti terhadap materi bahasan agar mendapatkan bahan masukan dan data pendukung dalam membangun gambaran utuh sistem.

\section{Metode Analisis Dan Perancangan}

Metode penelitian yang akan digunakan dalam perancangan aplikasi pelaporan pajak SPT Masa ini menggunakan metode RAD (Rapid Application Design). RAD adalah suatu model proses pengembangan sebuah perangkat lunak yang bersifat incremental atau bertingkat terutama untuk waktu pengerjaan yang cukup pendek. Model atau bentuk metode RAD adaptasi dari model air terjun (waterfall) versi kecepatan tinggi untuk pengembangan setiap komponen perangkat lunak. Pada tahap ini proses-proses dirancang dengan menggunakan diagram UML (Unified Modelling Language). (Dathan, Ramnath, Approach, \& Edition, 2015)

\section{Hasil dan Pembahasan}

Analisis dilakukan dengan mendiagnosis permasalahan dasar yang dialami oleh para Wajib Pajak di KPP Pratama saat proses pengurusan SPT Masa.

Tabel 1. Analisa Masalah

\begin{tabular}{|c|c|c|}
\hline No & Permasalahan & Pihak \\
\hline 1 & $\begin{array}{l}\text { Sistem yang berjalan saat ini masih manual } \\
\text { (menggunakan kertas) sehingga prosesnya lama dan } \\
\text { menimbulkan antrian panjang, sulit diperkirakan waktunya } \\
\text { kapan dapat dilayani, dan ruang tunggu yang kurang } \\
\text { menyenangkan }\end{array}$ & Wajib Pajak \\
\hline 2 & $\begin{array}{l}\text { Waktu pelayanan KPP terbatas hanya pada jam kerja } \\
\text { pelayanan. }\end{array}$ & Petugas KPP \\
\hline 3 & $\begin{array}{l}\text { Proses antrian WP tidak sesuai urutan antrian karena } \\
\text { masih menggunakan manual sering terjadi kesalahan } \\
\text { antrian }\end{array}$ & Wajib Pajak \\
\hline 4 & $\begin{array}{l}\text { Pencarian data wajib pajak,data transaksi pembayaran, } \\
\text { masih dicatat didalam buku. }\end{array}$ & Petugas KPP \\
\hline
\end{tabular}

Sumber: Hasil Penelitian (2019)

1. Wajib Pajak, a) memilih jenis SPT Masa, b) mengupload laporan SPT MasaWajib Pajak c) melakukan cek pelaporan SPT Masa.

2. Admin, a) mengkonfirmasi data Wajib Pajak, b) mengecek data users atau data users baru, c) mengkonfirmasi data laporan pajak baru.

Halaman awal berisi beberapa menu yang ada dalam aplikasi sistem informasi pelaporan penyampaian SPT Masa oleh wajib pajak. Tampilan halaman menu awal yang 
muncul adalah login. Tampilan menu awal berisi judul serta daftar menu. Pada layar login ini wajib pajak harus mengisi data NPWP dan Password yang sudah di daftarkan sebelumnya. Jika wajib pajak belum mendaftar, di bagian bawah layar ada tampilan menu Daftar Sekarang untuk bisa melakukan login.

Berikut activity diagram saat proses pendaftaran pelaporan SPT Masa:

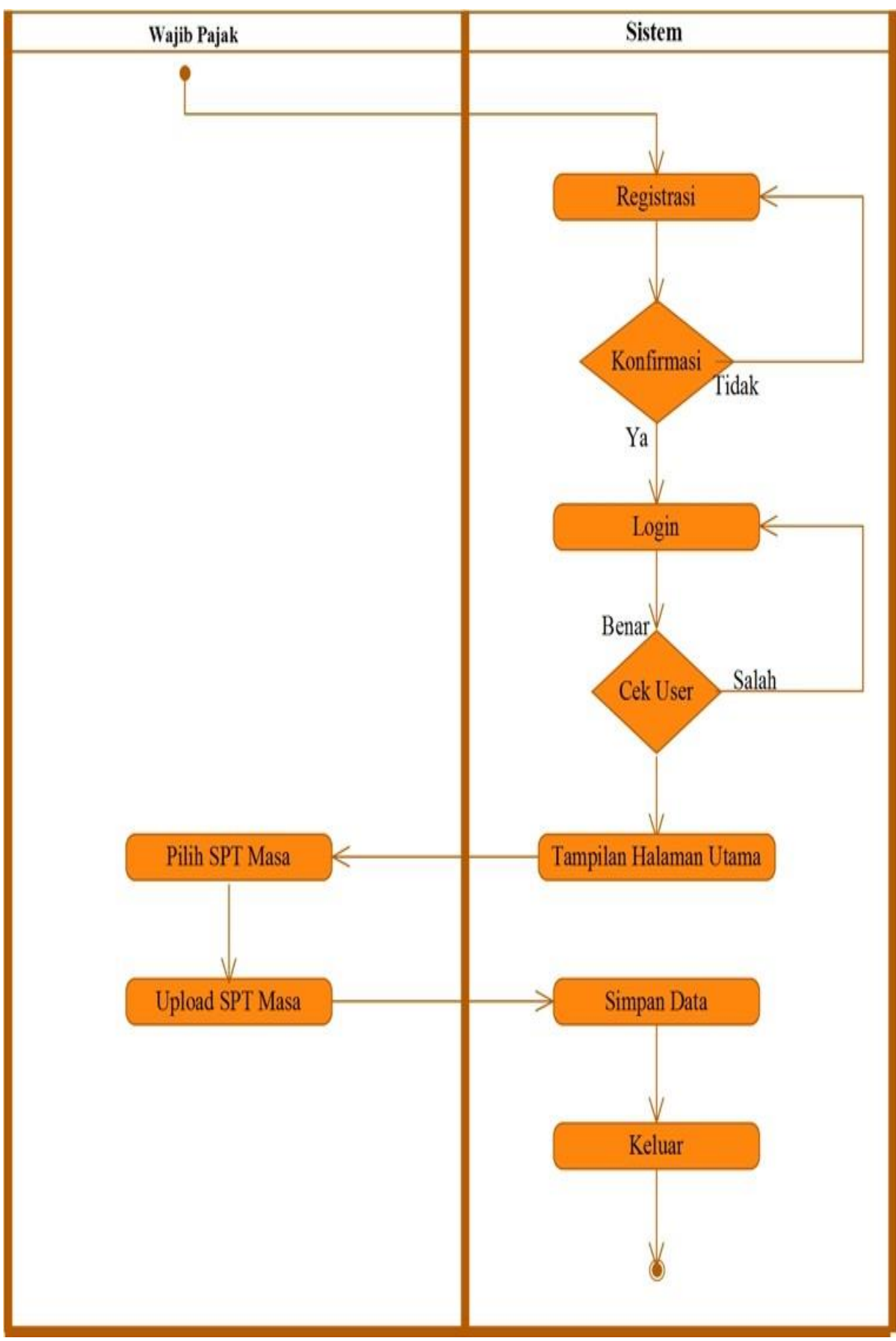

Sumber: Hasil Penelitian (2019)

Gambar 2. Activity Diagram Pelaporan SPT Masa 
Risa Septia Dewi, Kusdarnowo Hantoro, Sri Rejeki

Berikut adalah Sequence Diagram Pelaporan SPT Masa:

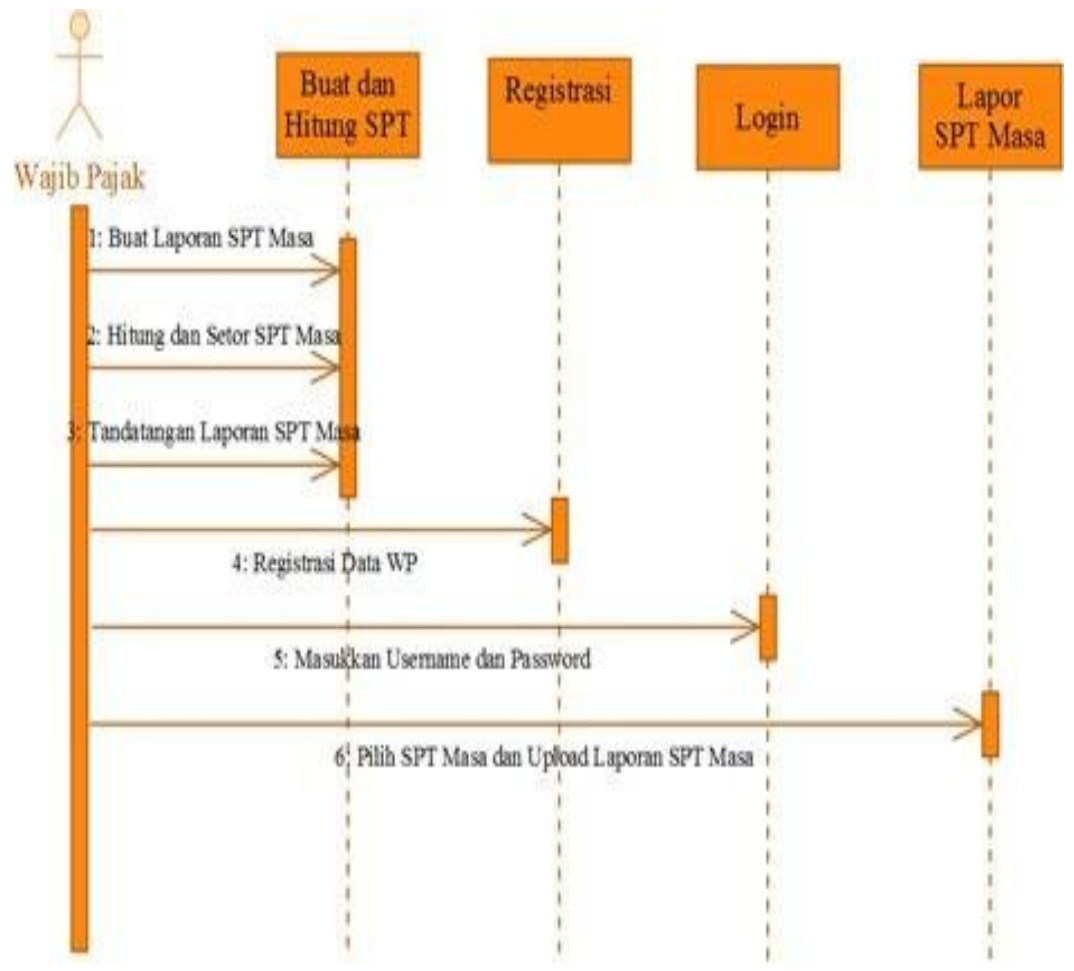

Sumber: Hasil Penelitian (2019)

Gambar 3. Sequence Diagram Pelaporan SPT Masa

Berikut adalah Class Diagram Pelaporan SPT Masa:

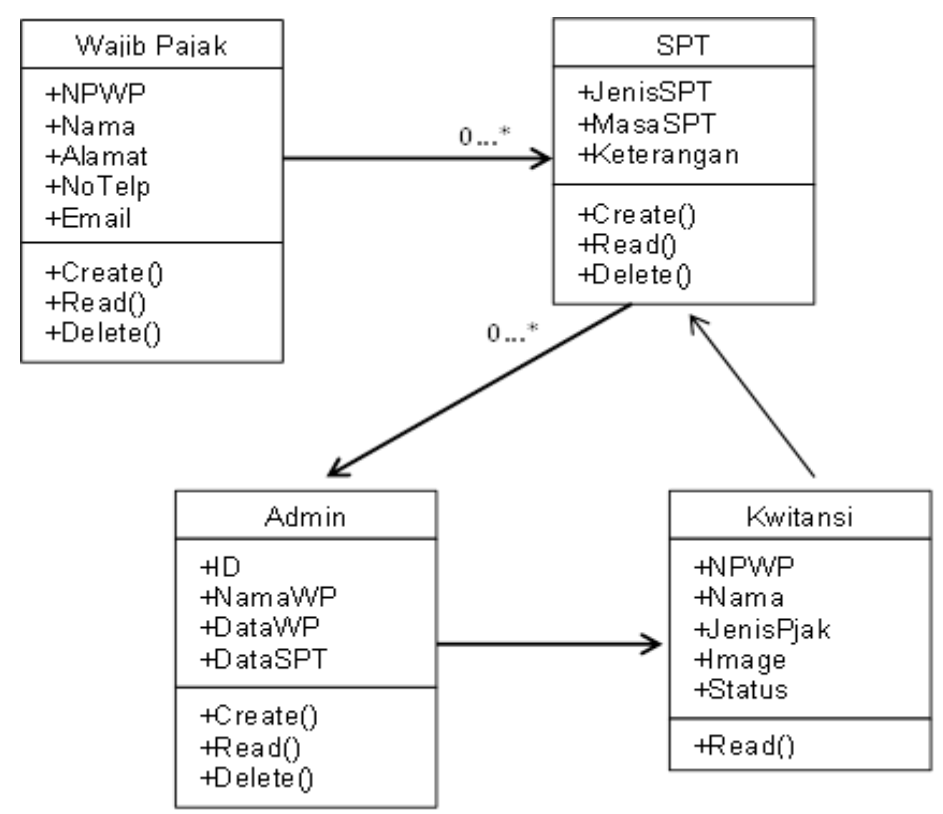

Sumber: Hasil Penelitian (2019)

Gambar 4. Class Diagram Pelaporan SPT Masa 


\section{Perancangan Basis Data}

Berikut adalah struktur data wajib pajak:

Tabel 2. Struktur Data Wajib Pajak

\begin{tabular}{|c|c|c|c|c|}
\hline$\overline{\text { No }}$ & Field & Tipe & Ukuran & Keterangan \\
\hline 1 & Id & INT & 11 & User_Name \\
\hline 2 & unique_id & var_char & 23 & Password \\
\hline 3 & Name & var_char & 50 & Nama Lengkap \\
\hline 4 & Email & var_char & 100 & Alamat Email \\
\hline 5 & Npwp & var_char & 30 & NPWP \\
\hline 6 & Alamat & Text & & Alamat Lengkap \\
\hline 7 & Kota & var_char & 30 & Kota \\
\hline 8 & Telp & var_char & 30 & No Telepon \\
\hline & encrypted_password & var_char & 80 & Password \\
\hline 10 & Status & Int & 1 & Status Konfirmasi \\
\hline
\end{tabular}

Sumber: Hasil Penelitian (2019)

Berikut adalah struktur data SPT:

Tabel 3. Struktur Data SPT

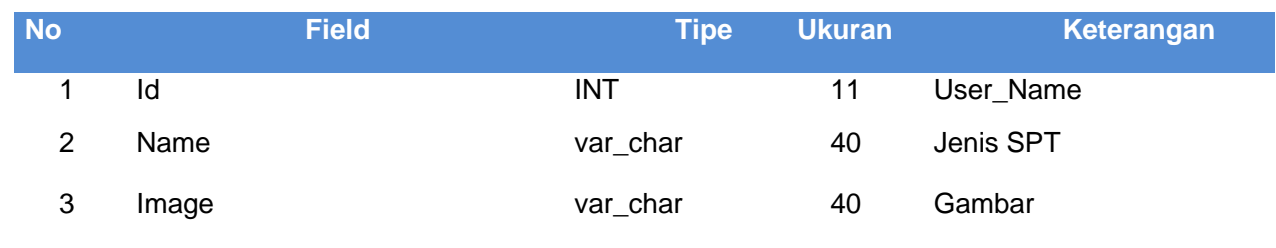

Sumber: Hasil Penelitian (2019)

Berikut adalah tampilan login Go-Pajak:

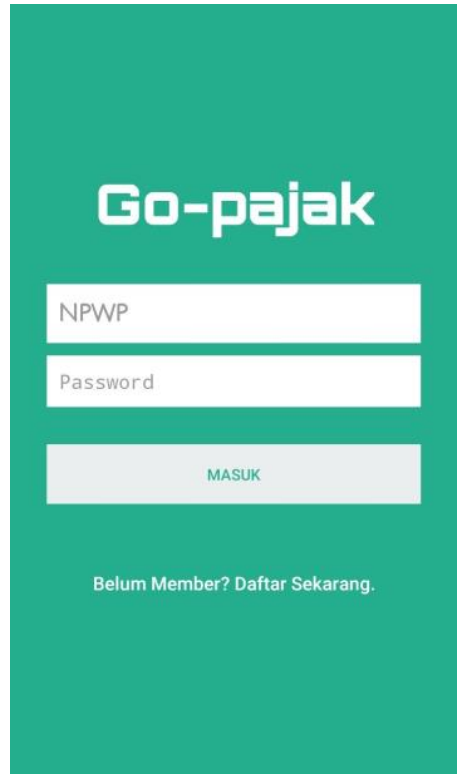

Sumber: Hasil Penelitian (2019)

Gambar 5. Tampilan Login 
Risa Septia Dewi, Kusdarnowo Hantoro, Sri Rejeki

Berikut adalah tampilan Registrasi WP:

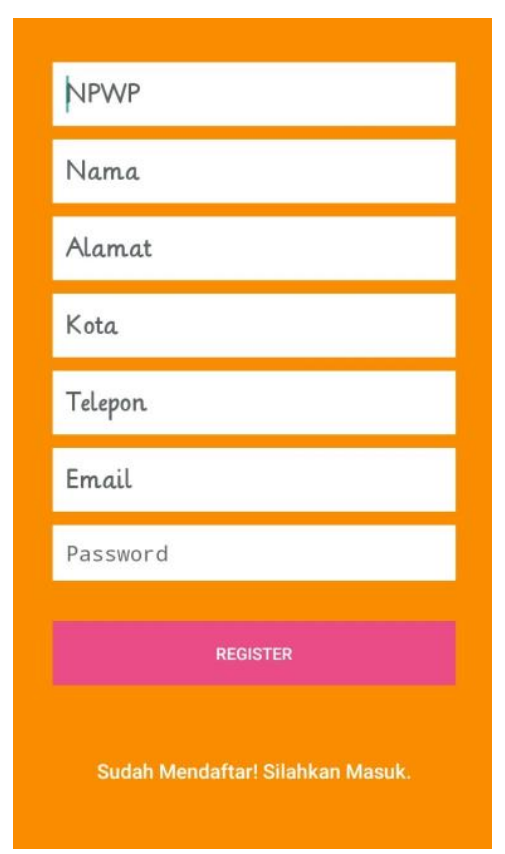

Sumber: Hasil Penelitian (2019)

Gambar 6. Tampilan Registrasi WP

Tampilan menu registrasi bertujuan untuk mendaftarkan data-data wajib pajak untuk bisa melakukan login dan sebagai identitas dari Wajib Pajak terdaftar. Pada Gambar 7 dijelaskan tentang tampilan pilihan jenis pembayaran.

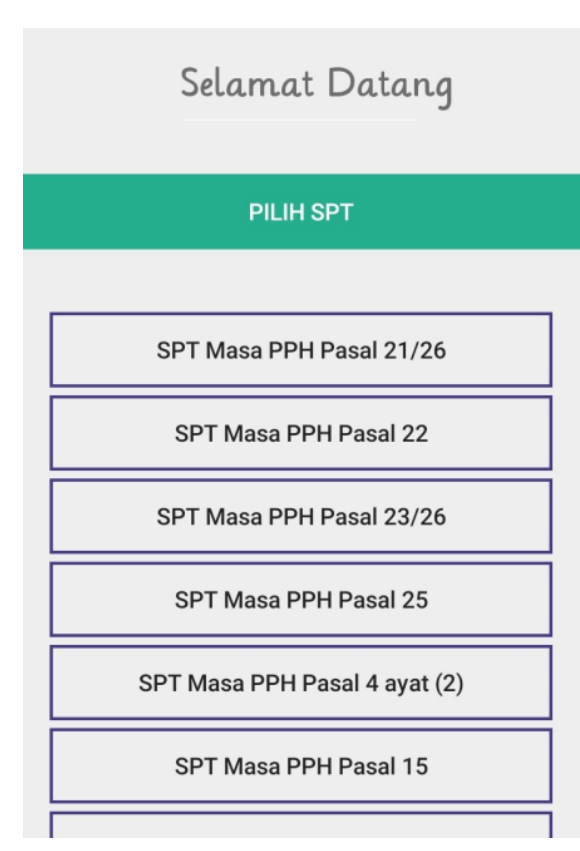

Sumber: Hasil Penelitian (2019)

Gambar 7. Pilihan Jenis Pembayaran 
Pada Gambar 8 dijelaskan tentang tampilan mengunggah dokumen pajak.

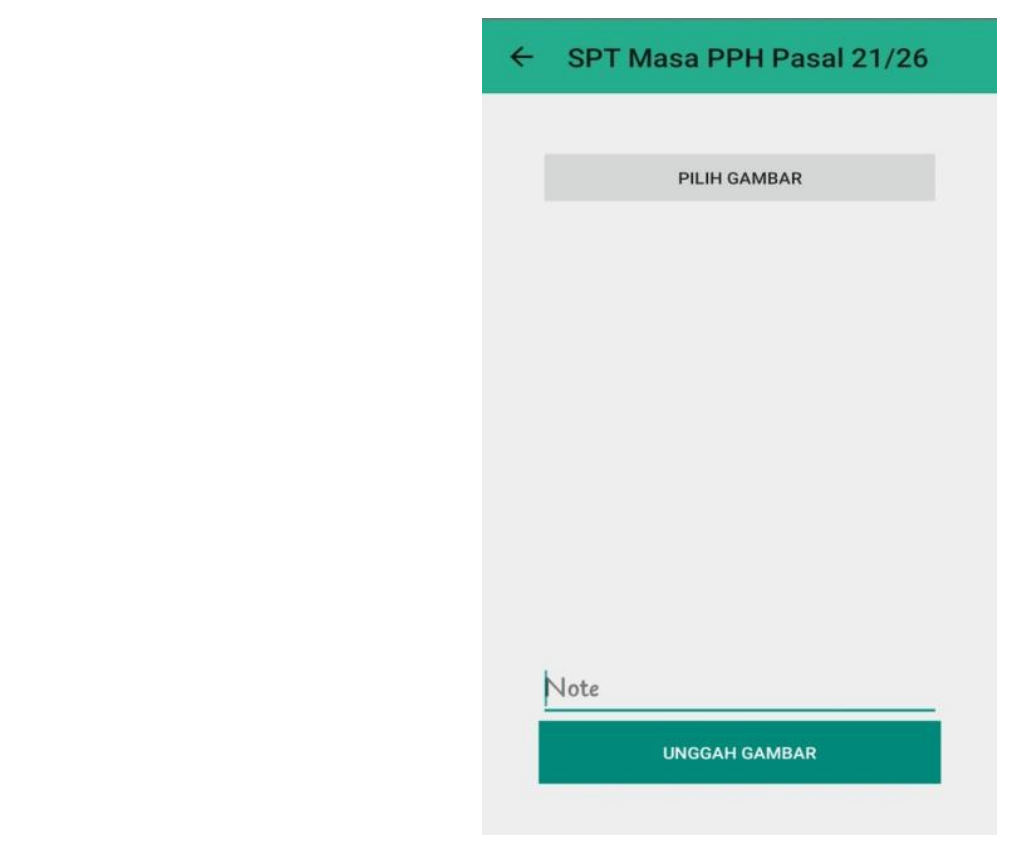

Sumber: Hasil Penelitian (2019)

Gambar 8. Mengunggah Dokumen Pajak

Setelah wajib pajak memilih daftar menu di Halaman Menu Utama, selanjutnya wajib pajak mempersiapkan laporan penyampaian SPT Masa yang sudah disiapkan dan ditandatangani. Selanjutnya wajib pajak memilih file serta menguploadnya. Halaman ini merupakan tampilan halaman untuk wajip pajak menyampaikan laporan SPT Masa. Setelah memilih jenis SPT Masa kemudian wajib pajak mempersiapkan laporan SPT Masa yang telah dibuat dan ditandatangani. Kemudian melaporkan nya dengan cara memilih atau mengupload gambar SPT Masa. Pada Gambar 9 dijelaskan tentang tampilan daftar peserta laporan pajak, sedangkan pada Gambar 10 dijelaskan tentang tampilan konfirmasi kwitansi.

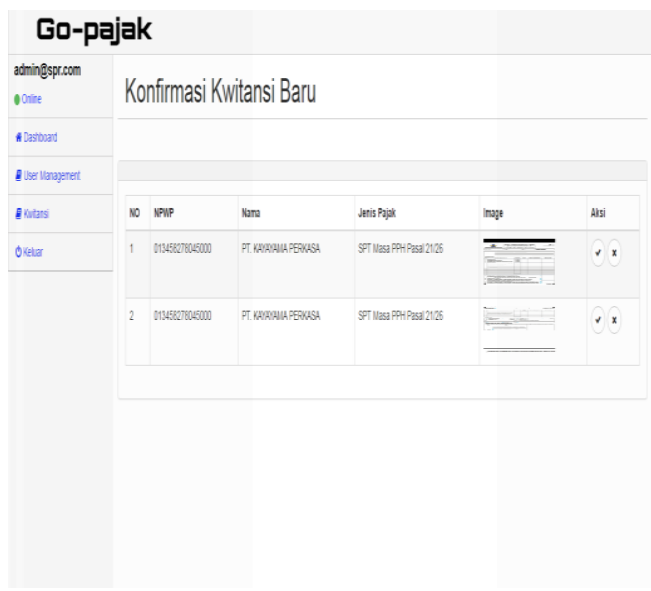

Sumber: Hasil Penelitian (2019)

Gambar 9. Daftar Peserta Laporan Pajak 


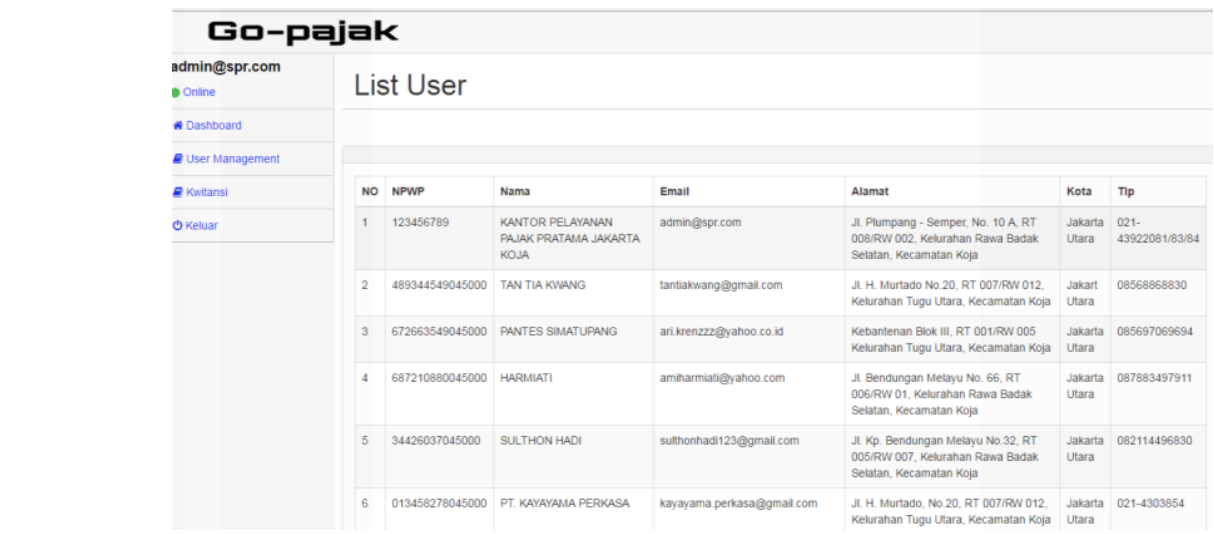

Sumber: Hasil Penelitian (2019)

Gambar 10. Konfirmasi Kwitansi

\section{Kesimpulan}

Berdasarkan pembahasan sebelumnya, maka dapat di ambil beberapa kesimpulan sebagai berikut: a) Diperlukan pengembangan sistem dalam memilih dan mengisi formulir SPT Masa agar tidak lagi mengisi formulir secara manual. b) Diperlukan pengembangan sistem laporan untuk perhitungan pajak sesuai dengan Undang-Undang Pajak yang telah di tetapkan. c) Diperlukan pengembangan sistem untuk tandatangan elektronik atau barcode sehingga tidak perlu lagi menandatangani laporan secara manual. d) Diperlukan pengembangan sistem informasi pelaporan penyampaian SPT Masa selanjutnya, agar sistem dapat diterapkan dan dilaksanakan dengan baik, maka perlu dianalisis kembali sehingga tidak menutup kemungkinan untuk dilakukan pengembangan sistem yang baru dan lebih baik.

\section{Daftar Pustaka}

Dathan, B., Ramnath, S., Approach, A. I., \& Edition, S. (2015). Object-Oriented Analysis, Design and Implementation. Springer.

Editors, S., \& Sharda, R. (2017). Design Research in Information System. Springer,Hamburg. Kesadaran, P., Pemahaman, P. D. A. N., Pelayanan, K., \& Sanksi, D. A. N. (2017). Pengaruh Sanksi Perpajakan, Pelayanan Fiskus, Pengetahuan Dan Pemahaman Perpajakan, Kesadaran Perpajakan Terhadap Kepatuhan Wajib Pajak. E-Jurnal Akuntansi, 6(3), 136148.

Prakoso, A., Wicaksono, G., Iswono, S., Puspita, Y., Bidhari, S. C., \& Kusumaningrum, N. D. (2019). Pengaruh Kesadaran Dan Pengetahuan Wajib Pajak Terhadap Kepatuhan Wajib Pajak. Jurnal Akuntansi \& Ekonomi, 4(1), 18-30.

Respati, N. D. (2020). THE ADOPTION OF E-GOVERNMENT IN THE TAX ADMINISTRATION : A SCOPING REVIEW. Scientax, 1(2), 109-130.

Wahyu Hidayat Ibrahim, I. M. (2017). Sistem Informasi Pelayanan Publik Berbasis Web Pada Dinas Pekerjaan Umum Kabupaten Kampar. Junal IImiah Rekayasa Dan Manajemen Sistem Informasi, 3(2), 17-22. 